\title{
Research on Ideological and Political Education in University English Teaching in Internet Era
}

\author{
Aiyang $\operatorname{Han}^{1, a}$ \\ ${ }^{1}$ Xisanhuan North Rd, Haidian District Beijing, China \\ amedi1114@126.com
}

Keywords: Internet; internet plus; English teaching; ideological and political education.

\begin{abstract}
The paper analyzes the importance of ideological and political education, the challenge that we will face in modern society. It is important to carry out ideological education in university English teaching. And we also the establishment and transformation of students' ideological thought in condition of high developing network. The knowledge form, teaching method and modes are analyzed. The implementation method of improving ideological and political education in English teaching on environment of internet plus and internet are provided. Finally, the existed problems and countermeasures to improve ideological and political education in internet era are presented. The results extend the span and force of enhancing ideological and political education in English education. The results have preferable theoretical values.
\end{abstract}

\section{Introduction}

In English teaching in college, the role of the network is increasing day by day. The information of the network makes students' information sources more abundant and diversified. Teachers' dependence on the network is more obvious, while the various information resources on the network greatly expand their teaching content [1]. Communication between teachers and students are more dependent on the network platform. The same is true of the ideological and political education in the Internet age. The diversity of the information sources of ideological and political education is more obvious. From the network, people can obtain a lot of positive and negative information, thus how to sort out the information and make the right guidance of information is very important. Teachers, in the selection of network resources, must select and extract information carefully. Through the network communication concerning ideological and political education becomes more frequently, which inquires more attention to the dynamic changes in network resources, and liquidity and dynamics of suitable information. In the process of English language teaching, the network information resource screening, positive information indoctrination and promotion are more important.

\section{Study on the Impacts of the Internet Age on College English Teaching}

(a) Analysis of the mode of college English teaching in the internet age

Compared with the traditional teaching mode, college English network teaching mode has three characteristics: First, decentralization. In the traditional classroom teaching mode, teachers being the center of the classroom, curriculum design, curriculum content and curriculum evaluation are led by the teacher. However, in the network teaching model, every cluster and node is equal, so each person can participate in curriculum design, choose their favorite courses, and participate in community interaction and curriculum evaluation according to their own learning preferences. Second, learning resource allocation is flexible and efficient. In the network teaching mode, high quality and scarce English learning resources can be obtained more simply, massive and high quality network education resources are applied at lower costs to students, and the common community will make learning resources more reasonable and efficiently allocated [2][3]. Third, the autonomy, distribution and real-time performance of leaning measures are improved. Compared 
with classroom teaching, the network teaching mode allows students to have more autonomy, which stimulates students' subjective will and self-learning ability to improve English achievement. Anytime in any place, through the network, students can choose their favorite English learning resources to learn. Online learning model also efficiently connects class and spare time.

(b) The Changes of English Education Mode Out of the Internet

Internet and information technology expand the ways of learning English. In the Internet age, due to the rise of personal computers and smart phones, in information exchange and access a major change has taken place. English learning methods have also undertook a lot of changes. In general, from static to dynamic, from offline to online, from independent to shared, the changes exist. For example, in the past, memorizing English vocabulary can only use the static "back dictionary" type, when students, in addition to the dictionary rote, basically had no other way, and the learning process is quite boring, which to a certain extent, also reduced the interest of students to learn. In the Internet era students can use mobile phone software and computer software to achieve multimedia ways of intelligent English dictionary learning, including mnemonic, review, test, forgetting analysis and other functions in one, and according to the forgotten curve automatic planning review program, pointing out learners' memory defects, which greatly improves the efficiency of vocabulary learning. In grammar, speaking, listening, reading and so on the Internet also provides a variety of learning methods.

(c) Recommendations on the Construction of College English Teaching Model in the Internet Era

In the Internet age, the traditional college English teaching should make a change, keeping the inheritance and innovating in the network teaching mode. The key to building the Internet teaching model in the Internet age is to change the mind, reshape the organization, reconstruct the core competitiveness and improve the security mechanism.

The first is to change the mental model to maintain the advancement of the teaching model. College English teachers should play the role of the leader, applying the methods of question inspiration, scene interaction and reflective discussion to drive students to learn.

\section{Study on College English Teaching Involving the Ideological and Political Education Approach}

(a) Main Problems and Analysis of Reasons Involving the Political and Ideological Education

Language is the product of society, the crystallization of human history and culture. It embodies the social consciousness, history and culture, customs and other aspects of human society of a nation which passes from generation to generation. Different cultural backgrounds and cultural traditions make cultural differences between China and the West in terms of ways of thinking, values, codes of conduct and lifestyles. Language is the carrier of culture, while vocabulary is the enrichment of cultural information, and an important part of language, which reflects the cultural development and change, but also directly reflects the cultural differences. With the strengthening of students' professional skills, students will use their own resources to learn, such as network news, English original books, English radio and so on. Through these channels, students get a lot of foreign information and more access to a wider range of Western culture. The original closed teaching mode has not been applied to modern teaching. English teachers have to teach and guide, so that students understand our historical development and the formation of traditional culture, and constantly improve their own quality, enhance their autonomy and creativity. As an English teacher, while self-improving, keeping pace with modern development, he should also pass the modern information to students, thus expanding their vision.

(b) Discussion on the Ways of Integrating Ideological and Political Education in College English Teaching

Teachers should guide students' socialist values in the education of language and culture. Western languages and words are engraved with the mark of capitalist values, so when teaching English, teachers have to integrate patriotism. In the public English classes in university, through introducing our socialist system and the Chinese traditional culture, students know that hardworking 
is a traditional virtue of the Chinese people. This traditional virtue is the objective requirement of the primary stage of socialism, but also the inevitable requirement of building a socialist harmonious society and revitalizing the national culture. It also reflects the inherent essence of loving the motherland and the socialist core values. In addition, we can learn from the Russian government, clearly putting forward that the government should increase the reward for outstanding teachers, update teaching equipment, teaching materials and publishing as an important part of a national "comprehensive project". In New Horizon English there is a sentence: do not ask your country can do something for you, ask you what you can do for your country. Sentences like this help students learn English language and culture while helping them establish loyalty to the nation.

In the implementation of ideological and moral quality education in colleges and universities based on China's historical and realistic conditions, in regulating the ideological and moral construction of college students, high schools resist the negative thinking of the West, establish a correct outlook on life and values. Colleges and universities take integrating the ideological and political education into the college public English teaching as the starting point to cultivating college students' noble moral sentiments, ideals and beliefs, and political beliefs. In college public English teaching, teachers should combine the specific content of English textbooks to contrast the cultural differences between China and the West, and tap the excellent cultural and moral qualities of our country. For example, Time is money, A year's plan starts with spring. Combining these sentences into personality quality education can increase students' interest. Due to the impact of Western culture, our college students do not understand some of our outstanding cultural and moral traditions, and instead worship Western culture and moral beliefs. In the English classroom timely integration of our excellent moral and cultural traditions to correct some of the students' thoughts and behavior of exorcism is helpful to make an ideal, faithful young generation.

\section{Studying on the Problems in Strengthening the Ideological and Political Education in English Teaching and Solutions in the Internet Era}

(a) Analysis on the Present Situation of Ideological and Moral Quality Education in College English Teaching

Due to the further opening of the domestic cultural market, especially the emergence of the Internet, these Western social thought, academic theory and other cultural products flourish. This open ideological environment provides colorful cultural experience to college students, while bringing some ideological confusion and behavioral choices on the plight to them. The culture carries ideology, values and lifestyles of the West into the campus, imperceptibly affects the ideological ideas of college students, dilutes our efforts to strengthen and improve the ideological and moral quality education, digests the patriotism, socialism, the value of collectivism guide. And college students are at the period of active thinking and plasticity of the period, some of them experiencing the crisis of faith, moral crisis, consumerism and hedonism and individualism and other decadent ideas. It is an urgent problem to follow up the pace of internationalization of higher education while meeting the impact of western ideology and culture and the ideological infiltration of international hostile forces. And English is a communicative language which plays a bridge role in the spread of Western culture. If we do not pay attention to cultivating students' ability to distinguish Western cultures, we may boost Western cultural infiltration rather than learn from all the outstanding achievements of all mankind. Therefore, it is imperative to implement ideological and moral quality education in English teaching.

(b) Methods of strengthening the teaching of ideological and moral education in English teaching

Therefore, we should consciously integrate ideological and moral quality education in the English education, infiltrate the ideological and moral quality of education into the specific English subject content, and combine the transfer of scientific knowledge and educate students, so that ideological and moral quality education can be felt, flesh and blood, possessing strong acceptability. In this way, the students will be able to select the positive and beneficial information resources, strengthen their foreign language ability and political thought, and also improve the ability of 
information identification; In addition, the infiltration of ideological and moral quality education in the English teaching takes a cumulative, subtle way without too much urgent requirements or the feeling of preaching, easy, solid and effective. Finally, it is possible to improve the self-selection ability of college students to face the correct Western culture and establish the correct value orientation and dialectical materialism world outlook and methodology. Through the Internet, students can obtain a wide range of ideological and political education information and cases, through analysis, strengthening their information identification and extraction capabilities, both to strengthen the English language teaching depth and breadth, but also effectively expanding the students' morality and accomplishment level. It is a useful extension of the ideological and political disciplines.

\section{Conclusion}

This paper starts from the point of college English teaching, studying the subject of ideological and moral quality education in the Internet age and under the new international and domestic situation, integrating the ideological and moral quality education into English teaching and supplementing with the Internet's interactivity and equality of the ideological and political education penetration theory in reality. The results of this study show that if the English language teaching activities do not implement the ideological and moral quality education principle, ideological and moral quality education can not really exist and strengthening the ideological and moral quality education will become empty talk. Therefore, this paper explores the theory and approach of strengthening the infiltration of ideological and moral quality education under the Internet conditions. The results have expanded the coverage and intensity of ideological and political education and have high theoretical value.

\section{References}

[1] Shen Xiao-yan. Research on the Reform of College English Teaching Mode in the Internet Age [J]. Overseas English, 2015 14: 65-66.

[2] Demin Li. Analysis on the Innovative Ways of Teaching Method for Ideological and Political Course in Colleges of the New Media Era. 2017 International Conference on Culture, Education and Financial Development of Modern Society [C], 2017, 103: 210-213.

[3] Yan Huang. A new way of ideological and political education under the network environment to explore. Journal of Culture, 2015 17: 26-29.

[4] Jing-Yun Wang. Concerning cultural carrier of ideological and political education in the new period of innovation and optimization. Academic Journal of Zhongzhou. (2012).

[5] Liang Du, Based on the $3 G$ era of mobile Internet ideological and political education innovation strategy. Ideology Education. (2010).

[6] Chen Zhao. Based on the mobile Internet ideological and political education effectiveness research. China's school education. (2014). 